\title{
Certain Responsibilities: Born to Privilege
}

\section{Eliza Koso ${ }^{1}$}

The author is a White, native English speaking, formally educated cis person who was raised Episcopalian. The author started critically thinking about issues of privilege and systemic discrimination while working at a non-profit organization, the Food Project. As the author has continued her education on such issues, she has reached an understanding that rather than feeling guilty, she must accept her responsibility to use her privilege to contribute to the dismantling of systems of oppression and challenge disenfranchisement. This piece began as a spoken word exploration into these issues and how one can face them in modern society. [Article copies available for a fee from The Transformative Studies Institute. E-mail address: journal@transformativestudies.org Website: http://www.transformativestudies.org (C2017 by The Transformative Studies Institute. All rights reserved.]

KEYWORDS: Systemic Discrimination, Privilege, Disenfranchisement.

White. Cis. Female.

American Born...American raised.

Bi-curious (though that might change)

Educated, Formally

Able-bodied, temporarily

All of these... pieces of my...Identity.

There is a way / we are taught...to be.

To properly flourish in Society

Now I know part of that / is to look...like...me.

I am not saying / I believe

Every trick I was born with / Up. My. Sleeve...

Is a blessing.

\footnotetext{
${ }^{1}$ Eliza Koso, undergraduate student at St. Lawrence University.
} 